\title{
REJOINDER TO ARTICLE BY DE BRUIN AND LEW: CONSTRUCT VALIDITY OF THE CAREER RESILIENCE QUESTIONNAIRE (CRQ)
}

\author{
LJ VAN VUUREN \\ C FOURIE \\ Programme in Industrial Psychology \\ Department of Human Resource Management \\ Rand Afrikaans University
}

\begin{abstract}
This rejoinder is presented in response to an analysis by De Bruin and Lew of the 1998 publication by Fourie and Van Vuuren on the career resilience construct. Comments and recommendations made by De Bruin and Lew in respect of the construct validity of the CRQ are responded to in terms of the theoretical foundation of the CRQ, the methodology used, the CRQ's content validity, sample-related issues, the instrument's construct validity, as well as a perspective on the future of the instrument.
\end{abstract}

\section{OPSOMMING}

Hierdie repliek word voorgehou na aanleiding van'n ontleding deur De Bruin en Lew wat op die 1998 -publikasie van Fourie en Van Vuuren aangaande die konstruk loopbaangehardheid, gebaseer is. Respons op die kommentaar en aanbevelings deur De Bruin en Lew aangaande die konstrukgeldigheid van die Loopbaan-gehardheidsvraelys (LGV) word voorgehou in terme van die teoretiese basis van die LGV, die metodologie wat gebruik is, die inhoudsgeldigheid van die LGV, die instrument se konstrukgeldigheid, steekproefverwante vraagstukke, asook 'n perspektief op die toekoms van die instrument.

A major concern for individuals pursuing careers in less than optimal career conditions within the new career paradigm is the enhancement of employability inside and outside their present employers' contexts. The phenomenon career resilience, of which the opposite condition appears to be career vulnerability, may be a critical competency of individuals to overcome adverse circumstances that impact career deployment and employability.

Since the career resilience concept is a relatively "new entrant" to the field of career management, any effort to contribute to the scientific exploration of career resilience is deemed to enhance the understanding of the theoretical framework of career resilience theory and imminent operationalisation thereof. The opportunity to respond to the special effort made by De Bruin and Lew in this regard, is therefore appreciated. Although each attempt at exploring and clarifying a construct such as this may contribute to its body of knowledge, it should, however, be borne in mind that the results of the studies on career resilience as referred to in this rejoinder, may all be regarded as sample-specific. Cross-validation is therefore ultimately required.

At he time of publication Fourie and Van Vuuren (1998) were fully aware of the need for further exploration of their findings by stating that "there are certain limitations to generalising and interpreting the findings of the study. In the first instance, the construct of career resilience is a complex phenomenon and research and inquiry into the nature thereof are not conclusive. Secondly, the reliability and validity of the Career Resilience Questionnaire (CRQ) as measuring instrument, have not been substantiated conclusively" (p. 58). This reinforces the scientific notion that no instrument is a constant - the continued development thereof is a function of continuous reciprocation between theory, research and practice. Blind empiricism is therefore not really an option when a construct like career resilience, and the CRQ as its descriptive measure, is scrutinised.

It has to be pointed out that the terms of the initial agreement on gaining access to and administering the CRQ, Lew (the second author) was explicitly alerted to the exploratory nature

Requests for copies should be addressed to: LJ Van Vuuren, Programme in Industrial Psychology, Department of Human Resource Management, RAU, PO Box 524, Auckland Park, 2006. of the Fourie and Van Vuuren (1998) study, and that the CRQ was still in the process of being validated. It was further agreed that findings and results would be shared. The De Bruin and Lew commentary therefore came as no surprise, since it was prompted by Fourie and Van Vuuren. De Bruin and Lew's work is viewed as a contribution that will certainly add value to the on-going analysis of the theoretical and statistical properties of the career resilience construct.

In response to De Bruin and Lew's findings, some comments regarding the theoretical foundation of the CRQ, the methodology used, the CRQ's content validity, sample-related issues, the instrument's construct validity, as well as a perspective on the future of the instrument, is provided henceforth.

\section{Theoretical foundation of the CRQ}

At the time of the Fourie and Van Vuuren (1998) study, the earlier research on resilience as a construct that may have application in the field of career management, was limited. Nor was there an instrument to measure career resilience more comprehensively than the seven- and 13 item-approaches by London (1983, 1993) and Noe, Noe and Bachhuber (1990) provided for. London (1983), in his initial exploration of the concept, conceded that the dimensions of career resilience are neither independent nor necessarily exhaustive of all possible important constructs. In confirming London's initial reservations, De Bruin and Lew allude to the fact that "no explicit theoretically derived multi-dimensional model of career resilience is given" in the Fourie and Van Vuuren (1998) article. The latter research report was, however, based on the, albeit few, efforts of Bridges (1995), Gordon and Coscarelli (1996), London $(1983,1993)$ and Noe, et al. (1990), who pioneered attempts to describe and delineate the construct in terms of its importance and utility.

The intention with the 1998 study by Fourie and Van Vuuren was not to develop such a model, but to explore the concept that was originally coined by London (1983) as a dimension of his multidimensional theory of career motivation. In line with this aim it was decided to define and describe career resilience within the new career paradigm, and to develop a measuring instrument that may enable the researchers to shed more light on the concept than initial London $(1983,1993)$ and Noe, et al. (1990) findings allowed for. 
The process of theorising is necessarily intuitive, perhaps even more so in the case of exploratory research. It also has to be pointed out that for a study of an exploratory nature, a domain of observables have to be outlined before the observables can relate to a construct. In the Fourie and Vuuren (1998) study several observables relating to competencies, attitudes and orientations required of careerists in the so-called new career paradigm, were explored. Thereafter the domain of career resilience was outlined. This can be seen from the way in which Fourie and Vuuren (1998, pp. 53-54) describe the behavioural component of career resilience.

It should be noted that a research project aimed at an in-depth exploration of career resilience, the effort of which may result in exactly such a "multi-dimensional model of career resilience" that De Bruin and Lew recommends, was initiated by the present authors in April 2001.

\section{Methodology}

In order to obtain a simple structure of the constructs when doing factor analytic studies, the present authors normally make use of the pattern matrix rotated according to the direct oblimin procedure. This is evident from Table 4 in Fourie and Van Vuuren (1998). De Bruin and Lew describe their use of factor structure coefficients to report on the correlations between the items and factors of the CRQ. Whilst the present authors agree with the factor analytic method used by De Bruin and Lew, the reporting of the structure matrix rather than the pattern matrix is unusual (cf. Tabachnick \& Fidell, 1996), as the structure matrix seldom reflects the underlying simple factor structure. Tabachnick and Fidell (1996) note that there is some debate as to whether the pattern matrix or the structure matrix should be interpreted after oblique rotation has been executed. They further explain that "the correlations between variables and factors are inflated by any overlap between factors. The problem becomes more severe as the correlations among factors increase and it may be hard to determine which variables are related to a factor. On the other hand, the pattern matrix contains values representing the unique contributions of each factor to the variance in the variables. Most researchers interpret and report the pattern matrix rather than the structure matrix (p. 653) (emphasis by present authors). This probably explains why De Bruin and Lew describe their Table 2 as revealing "a very complex factor solution" and "shows that several items are factorially complex, having more than one salient factor structure coefficient". It would therefore have been interesting to see the pattern matrix produced by De Bruin and Lew's data.

\section{Content validity}

De Bruin and Lew recommend, amongst others, that items in a questionnaire of career resilience should demonstrate face validity. It should be noted that the CRQ items were initially trialled, as is customary in questionnaire construction, and was also published in the public domain (Fourie \& Van Vuuren, 1998). De Bruin and Lew decided to include and administer the CRQ in their study after having had the opportunity to inspect the items (and thus the face validity thereof). It is therefore assumed that the face validity of the CRQ's items was of a sufficient standard to warrant an application of the questionnaire in its original format, and without improvement of any items.

In compiling the range of items of the CRQ, particular care was exercised by Fourie and Van Vuuren not to formulate the same item in 60-something different forms to ensure a high reliability coefficient, but to comprehensively cover the domain of the career resilience construct as it existed at the time of the research. Kerlinger and Lee (2000) suggest that "it is possible and desirable to assemble large collections of items, especially in the achievement area. But the content validity, no matter how large and "good" the items, is always in question. Content validation consists essentially in judgment" (p. 667) (emphasis by present authors). The 60 items that initially comprised the CRQ was a representative sample of items, based on judgement, that could potentially have been included in a such a questionnaire. As is the norm for research of this type, a special effort was made to achieve the highest possible content validity of the CRQ. The 45 items that were retained by means of item analyses are therefore regarded to be representative of the career resilience domain that was explored in the Fourie and Van Vuuren (1998) study.

De Bruin and Lew comment on items 7, 8 and 38. These items, on face value, seem to be aligned to career resilience theory. The current state of career resilience theory indicates that the construct is very much concerned with individuals' inclination to take charge of their careers by exploring alternative career management approaches in uncertain or adverse situations. Even though item 38 may not directly reflect adverse career situations, it represents an attempt to establish the extent to which respondents perceive job security and the traditional paradigm of extended employment in a particular organisation, to be of less importance in the new career paradigm. Items 7 and 8 seem to adequately assess attitudes that reflect individuals' willingness to be assertive in career situations that require more ingenuity than traditional ways to identify alternative career strategies provide for.

\section{Sample}

The Fourie and Van Vuuren (1998) study ( $=352)$ was an exploratory study, the results of which were based on responses by a sample drawn from employees who were positioned in industries (motor manufacturing and short-term insurance) that were deemed to be less than stable insofar as continued job security and extended organisational membership were concerned. This may then have required that the respondents constituting the sample may have been required to revisit expectations around opportunities for continued career growth and progression. This, in turn, may have required some form of career resilience. Irrespective of this, as can be seen clearly form the Fourie and Van Vuuren (1998) Discussion section, no recommendations were made regarding the generalisation of empirical results. As such, the recommendations focused on the possible value of career resilience, as becomes a study in which a relatively new construct is explored.

The question has to be raised as to whether the differences evident between the results of the Fourie and Van Vuuren (1998) and De Bruin and Lew studies, could be attributed to some psychological differentiation that may exist between the samples of the two sets of researchers respectively. The effect of this should not be disregarded: validity is necessarily a function of the interaction that exists between participants of a sample and their particular context. What is valid for one sample, is not necessarily valid for another. Insofar as career resilience is concerned, it can be stated that the complex nature of the concept, and therefore the domain of observables, may be interpreted differently by different research samples. Furthermore, the contextual setting of adverse circumstances and chronic or infrequent career barriers that may be present for one set of participants, may be rather different from those perceived by another sample.

\section{Construct validity of the CRQ}

Anastasi (1986) explains that a validation process begins with psychological theory, prior research, or observation and analyses of the relevant behaviour domain. As was explained previously, the 45-item Fourie and Van Vuuren (1998) Career Resilience Questionnaire (CRQ) resulted from an approach based on observation and analysis of the relevant behaviour domain. The four scales derived (consisting of 14, 7, 9 and 15 items) presented Cronbach alphas of $0.73,0.68,0.62$ and 0.72 respectively. De Bruin and Lew state, somewhat ambiguously, that "it is obvious that the reliability coefficients of the scales range from marginally satisfactory $(=0.730)$ to unsatisfactory $(=0.617)$ suggesting that the items in the four scales are conceptually somewhat disconnected and not tightly clustered". 
Since reliability sets the upper bound to validity, a measuring instrument can generally be reliable but not necessarily valid for a particular purpose. However, it cannot be valid and unreliable. With an ability or achievement test the minimum acceptable reliability coefficients are deemed to be 0.7 or higher. Once again the reliability coefficient is an estimate, of a particular type based on a particular sample of respondents.

It has to be pointed out that the CRQ is a questionnaire. In this case a questionnaire that is intended merely as a tool to be utilised in career management programmes and interventions. The instrument is not a clinical instrument that provides absolute or conclusive estimates or predictions on career behaviour. Nor is it a test upon which major life decisions can be based. Ideally the CRQ is to be used as an instrument that can be used, in conjunction with other interventions, to explore issues, foster self-insight and create dialogue about career management behaviours that can be capitalised on or potentially put an individual at risk in the new career paradigm. The CRQ may, however, be used to identify patterns of resilience-related behaviour - these patterns may be explored further during discussions aimed at future career planning. Since no "prediction" of future performance is made, it is therefore certainly acceptable for the reliability coefficients of an instrument of this type to be lower than those usually sought for tests of ability for example. Although continued validation may be sought, the validity information available for the CRQ suggests that is has reached an acceptable level for the particular application as described above.

An analysis of the Fourie and Van Vuuren (1998) data reveals that the items of each scale displays statistically acceptable variance. Each item of a particular scale is therefore a miniature version of the scale as a whole. De Bruin and Lew suggest that there are too few items per scale. In practical terms, however, this does not mean that the items that were eventually retained were necessarily weak. Furthermore, the intercorrelations between the scales are low. This implies that the scales are relatively independent. Depending on a broadening of the career resilience research basis in the future, and the eventual practical application of the CRQ, care will still have to be taken not to include too many items in the questionnaire - few employees have the time, or the inclination, to respond to questionnaires that contain excessive numbers of items.

The fact that the scale reliabilities "range from marginally satisfactory $(=0.730)$ to unsatisfactory $(=0.617)$..., in De Bruin and Lew's words, is acknowledged and indicates that the CRQ does need some refinement. The need for this is further underlined by the results of a study $(\mathrm{N}=176)$ by Botha (2001), in which reliabilities of $0.72,0.56,0.63$ and 0.73 were obtained for the four existing CRQ-scales respectively.

\section{The future of the CRQ}

As has already been stated by Fourie and Van Vuuren (1998), as well as De Bruin and Lew, career resilience may be an important competency for careerists to demonstrate and/or foster in the face of the demands posed by the new career paradigm of less than optimal conditions devoid of the conventional definition of career success, e.g. progression "up the corporate ladder". Further, in-depth theoretical and empirical analyses of the construct are therefore imperative. As has been mentioned earlier in this discussion, a first step in this direction may be the research project aimed at an in-depth exploration of career resilience which has already been under way since April 2001 - the De Bruin and Lew call for the development of a "multi-dimensional model of career resilience" had thus been pre-empted to an extent.
Anastasi (1986) emphasises that "Construct validation is indeed a never-ending process" (p. 4). No measuring instrument in the field of psychology is perfect - further refinement of the CRQ is therefore imminent. A possible first step in this quest may be to combine the Botha (2001), Fourie and Van Vuuren (1998), and De Bruin and Lew data sets. Statistical analyses performed on data from a sample size in excess of 700 may yield somewhat different results from those that have thus far been obtained independently.

\section{CONCLUSION}

The importance of peer review type systems that make provision for reminding researchers of the importance of scientific and academic integrity, and that allow for objective questioning and scrutiny of research results previously published, is once again underscored by the commendable effort made by De Bruin and Lew to challenge the construct validity of the CRQ. It is through efforts like these that the field of industrial psychology can grow through continued theorisation and measurement of new constructs, in this case career resilience. Furthermore, the erudite statistical analysis of the CRQ that resulted from De Bruin and Lew's effort must have been conceptualised within a broader theoretical framework and ideas on career resilience, rather than being based on serendipity. This is clear from the title of the broader research project on which their commentary was based, namely "A factor analytic study of adult career concerns, career status and career resilience" (Lew, 2001). Over and above the contribution of the empirical information contained in the Lew study to the future development of the career resilience construct, the theoretical information contained therein may be of particular significance for the growth of the construct. Future contributions and possible co-operation with the present authors may create some synergy that bodes well for the continued development of the career resilience construct.

\section{REFERENCES}

Anastasi, A. (1986). Evolving concepts of test validation. Annual Review of Psychology, 37, 1-15.

Botha, E.M. (2001). Is affirmative action an issue for career resilient white males? Unpublished dissertation. Johannesburg: Rand Afrikaans University.

Bridges, W. (1995). Jobshift: how to prosper in a world without jobs. London: Brealey.

Fourie, C. \& Van Vuuren, L.J. (1998). Defining and measuring career resilience. Journal of Industrial Psychology, 24(3), 52-59.

Gordon, K.A. \& Coscarelli, W.C. (1996). Recognizing and fostering resilience. Performance Improvement, 35(9), 14-17.

Kerlinger, F.N. \& Lee, H.B. (2000). Foundations of behavioral research (4th ed.). Fort Worth, TX: Harcourt.

Lew, C.C. (2001). A factor analytic study of adult career concerns, career status and career resilience. Unpublished doctoral dissertation. Johannesburg: Rand Afrikaans University.

London, M. (1983). Toward a theory of career motivation. Academy of Management Review, 8(4), 620-630.

London, M. (1993). Relationships between career motivation, empowerment and support for career development. Journal of Occupational and Organizational Psychology, 66, 5569.

Noe, R.A., Noe, A.W. \& Bachhuber, J.A. (1990). An investigation of the correlates of career motivation. Journal of Vocational Behaviour, 37(3), 340-356.

Tabachnick, B.G. \& Fidell, L.S. (1996). Using multivariate statistics. New York: Harper Collins. 